\title{
Relationship between risk factors and in-hospital mortality due to myocardial infarction by educational level: a national prospective study in Iran
}

Ali Ahmadi ${ }^{1}$, Arsalan Khaledifar ${ }^{2}$, Homeira Sajjadi ${ }^{3}$ and Hamid Soori ${ }^{4^{*}}$

\begin{abstract}
Introduction: Since no hospital-based, nationwide study has been yet conducted on the association between risk factors and in-hospital mortality due to myocardial infarction (MI) by educational level in Iran, the present study was conducted to investigate relationship between risk factors and in-hospital mortality due to Ml by educational level.

Methods: In this nationwide hospital-based, prospective analysis, follow-up duration was from definite diagnosis of MI to death. The cohort of the patients was defined in view of the date at diagnosis, hospitalization and the date at discharge (recovery or in-hospital death due to MI). 20750 patients hospitalized for newly diagnosed MI between April, 2012 and March, 2013 comprised sample size. Totally, 2511 deaths due to MI were obtained. The data on education level (four-level) were collected based on years of schooling. To determine in-hospital mortality rate and the associated factors with mortality, seven statistical models were developed using Cox proportional hazards models.

Results: Of the studied patients, 9611 (6.1\%) had no education. in-hospital mortality rate was 8.36 (95\% Cl: 7.81-8.9) in women and 6.12 (95\% Cl: 5.83-6.43) in men per 100 person-years. This rate was 5.56 in under 65-year-old patients and 8.37 in over 65 -year-old patients. This rate in the patients with no, primary, high school, and academic education was respectively 8.11, 6.11, 4.85 and 5.81 per 100 person-years. Being woman, chest pain prior to arriving in hospital, lack of thrombolytic therapy, right bundle branch block, ventricular tachycardia, smoking and ST-segment elevation myocardial infarction were significantly associated with increased hazard ratio (HR) of death. The adjusted HR of mortality was 1.27 (95\% Cl: 1.06-1.52), 0.93 (95\% Cl: 0.77-1.13), 0.72 (95\% Cl: 0.57-0.91) and 0.82 (95\% Cl: 0.66-1.01) in the patients with respectively illiterate, primary, secondary and high school education compared to academic education.
\end{abstract}

Conclusion: A disparity was noted in post-MI mortality incidence in different educational levels in Iran. HR of death was higher in illiterate patients than in the patients with academic education. Identifying disparities per educational level could contribute to detecting the individuals at high risk, health promotion and care improvement by relevant planning and interventions in clinics and communities.

Keywords: Myocardial infarction, Educational level, In-hospital mortality, Risk factor, Iran

\footnotetext{
* Correspondence: hsoori@yahoo.com

${ }^{4}$ Safety Promotion and Injury Prevention Research center, Department of Epidemiology, School of Public Health, Shahid Beheshti University of Medical Sciences, 7th Floor, 2nd SBMU Headquarters Building, Parvaneh St., Velenjak Area, Chamran High Way, Tehran, Iran

Full list of author information is available at the end of the article
} 


\section{Introduction}

Myocardial infarction (MI) is one of the most important health challenges in western and non-western communities, including Iran [1,2]. Despite promotion and usage of new therapeutic approaches, the morbidity and mortality relevant to MI are on rise in Iran and other Asian countries [3,4].

In view of the findings in different studies, the decreasing and/or increasing trend of MI and the associated mortality is not equally distributed in all population groups [5-7]. Relationship between health and socioeconomic status (SES) was reported in various works [8-10]. This correlation was also noted between SES, such as educational level (EL), income, occupation, and MI incidence and the associated mortality $[11,12]$.

In a meta-analysis, a strong association was reported between MI incidence and low SES. An overall increased risk of MI among in low SES was found for all three indicators; income (relative risk $[\mathrm{RR}]=1.71,95 \% \mathrm{CI}$ : 1.43 2.05), occupation ( $R R=1.35,95 \% \mathrm{CI}: 1.19-1.53)$ and education $(\mathrm{RR}=1.34,95 \% \mathrm{CI}: 1.22-1.47)$.

The strongest associations were seen in high-income countries, such as the USA and Canada, and Europe, while the results were inconsistent or vague for middle and low-income countries [13]. Inconsistent findings seem to be attributable to the selection bias, nonresponsive, self-selection bias, information bias and limited number of prospective studies $[14,15]$. Other reasons for this inconsistency could be the difference in MI incidence rate, various genetic, lifestyle, and environmental factors or disparity of the disease risk factors in different SES. This issue requires further investigation in subsequent works.

Education has been hired as a proxy for SES in 30 studies in the Netherlands, Italy, Switzerland, Estonia, Finland, Denmark, France, Australia, Spain, Belgium, Lithuania, and Spain $[13,16]$. In Germany, the best index for assessing SES and disparity in health is education [17]. Validity and reliability of the above indices seem to be different in various communities. Education affects health both directly and indirectly. This index could be assessed for all individuals of the community. This measure is a strong predictor of health outcomes. In Iran, the economic data are not usually reliable, as with many other countries worldwide. The individuals could have more than one occupation and various income sources at the same time and be unwilling to mention their actual income [18-20]. Investigation of the relationship between MI incidence and in-hospital mortality determinants and identifying disparities per educational level could contribute to detecting the individuals at high risk, health promotion and care improvement by relevant planning and interventions in clinics and communities. Since no hospital-based, nationwide study has been yet conducted on the association between risk factors and in-hospital mortality due to myocardial infarction by educational level in Iran, the present study was conducted to study relationship between risk factors and in-hospital mortality due to MI by educational level.

\section{Methods}

This is a prospective, hospital-based study in national scale in Iran. In this study, the data of 20750 MI cases registered in Iranian Myocardial Infarction Registry (IMIR) were used. IMIR collects the data from cardiac care units (CCUs) of all hospitals across the country [21]. All participants were patients hospitalized for newly diagnosed MI at 540 hospitals between April, 2012 and March, 2013. MI diagnosis was made using the criteria of the International Classification of Diseases-10th version (the code: I21) by the cardiologist [22]. The assessment of risk factors including blood pressure, diabetes, MI complications, place of MI, and the type of MI treatment was done based on the protocol codified by World Health Organization and Iran Ministry of Health and Medical Education per the information in the patients' medical records (blood pressure of higher than 140/ $90 \mathrm{mmHg}$ and fasting blood sugar of higher than $126 \mathrm{mg} / \mathrm{dl}$ were defined as respectively hypertension and type 2 diabetes). Years of schooling were categorized as zero year (no education or illiterate); $1-5$ years (the first level or primary); 6-9 years (the second level or guidance); 10-12 years (the third level or high school); and more than 12 years (fourth level or academic), together used as a 4-mode variable for educational level.

The chi-square test was used to test for differences in frequencies, and student's t-test and analysis of variance (ANOVA) were used to test for differences in continuous variables between groups. In-hospital mortality rate in the patients was calculated in person-year in the cohort of the patients defined by the date at diagnosis, hospitalization duration, and the date at discharge (recovery or death due to MI in hospital). In-hospital case fatality rate was calculated by the number of in-hospital MI death divided by number of reported hospitalizations due to registered MIs. For modeling and determining the factors relevant to in-hospital mortality per education, Cox proportional hazard models were used. In this prospective analysis, study follow-up was from definite diagnosis of MI to death. Totally, 3724983 person-years follow-ups were undertaken for 2511 deaths. The presuppositions of Cox model were checked and, except lack of thrombolytic therapy and ventricular tachycardia, were confirmed using Schoenfeld residuals (Ph test).

Firstly, all patients were classified by education and Cox analysis was run for each level of education. Then, Cox analysis was repeated for all patients with inclusion of different variables, such as educational level. Hazard 
ratio of mortality was calculated as crude in each educational level in zero model. Entering different variables, adjusting potential confounding variables in seven-mode models, and considering academic education as reference, we calculated the death $\mathrm{HR}$ in the patients by education as follows:

The first model was developed by age (quantitative) and gender; the second model by combination of the first model and its interaction with gender and EL; the third model by combination of the second model and history of the risk factors consisting of smoking, hypertension, diabetes, and blood lipid disorder; the fourth model by combination of the third model and therapeutic regimen such as thrombolytic therapy, percutaneous coronary intervention (PCI), and coronary artery bypass grafting (CABG); the fifth model by combination of the fourth model and ischemic pain pattern; the sixth model by combination of the fifth model and MI complications such as cardiac blocks, like left bundle branch block (LBBB), right bundle branch block (RBBB), ventricular fibrillation (VF), ventricular tachycardia (VT), and atrial fibrillation (AF); and the seventh model by combination of the sixth model and place and type of MI (anterior, posterior, inferior, lateral, ST-segment elevation myocardial infarction [STEMI], and non STEMI).

Myocardial infarctions are generally classified into STEMI and non STEMI. Electrocardiogram (ECG) testing was used to differentiate between two types of MI based on the shape of the tracing. For a person to qualify as having an STEMI, the ECG must show new ST elevation in two or more adjacent ECG leads. Considering seven-mode models, we developed the final model of patients' mortality determinants with inclusion of education and other risk factors. To report in-hospital mortality rate, the date of birth was defined as an origin variable. To control the effect of age as a confounding variable, date of birth was used as the origin of time in Cox models and hence age was not reported in model. All analyses were done by Stata 12 Software.

\section{Results}

Of 20750 studied patients, 9611 (46.32\%) had no, 4941 (23.81\%) primary, 1940 (9.35\%) guidance, 2992 (14.42\%) high school, and 1266 (6.1\%) academic education. The mean age, hospitalization duration, the prevalence of risk factors like hypertension, diabetes, smoking, place and type of MI, complications, and type of treatment are shown in Tables 1 and 2 for educational levels. The inhospital mortality rate due to MI was 8.36 (95\% CI: 7.81-8.9) in women and 6.12 (95\% CI: 5.83-6.43) in men per 100 person-years. This rate was 5.56 (95\% CI: 5.245.87) in under 65-year-old patients and 8.37 (95\% CI: 7.93-8.84) in over 65-year-old patients per 100 personyears. In-hospital mortality in the patients with no, primary, high school, and academic education was respectively $8.11,6.11,4.85$, and 5.81 per 100 person-years respectively. The highest In-hospital mortality (15.37) was obtained in the women under 65 years with academic EL followed by the women above 65 years academic EL (13.04) and illiterate women above 65 years (10.66). The In-hospital mortality with $95 \%$ CI is shown in Table 3 for gender, age, and education. In-hospital case fatality rate in total patients and the patients with no, primary, high school, and academic education was respectively $12.1 \%, 14.7 \%, 11 \%, 8.4 \%$ and $11.3 \%$. The crude HR of mortality was $1.41,1.05,0.78$ and 0.83 in the patients with respectively no, primary, secondary and high school education compared to those with academic education. Controlling confounding variables, we illustrated the above ratios with $95 \%$ CI for seven-mode models in Table 4.

The adjusted HR of mortality was $1.27,0.93,0.72$, and 0.82 in the patients with respectively no, primary, secondary, and high school education compared to those with academic education in the multivariate analysis. The significant determinants in the final Cox model of the patients' mortality are shown in Table 5 for total patients. The HR of mortality for diabetes mellitus in univariate analysis was significant (HR: 1.1, 95\% CI: 1-1.2,

Table 1 Demographic and medical characteristics in MI patients by educational levels in Iran, 2012-2013

\begin{tabular}{|c|c|c|c|c|c|c|}
\hline Characteristic & Total $\mathbf{n}=\mathbf{2 0 7 5 0}$ & Illiterate $n=9611$ & Primary $n=4941$ & Secondary $n=4932$ & University $n=1266$ & P-Value \\
\hline Age (year)* & $61.2 \pm 13.4$ & $67.7 \pm 12$ & $58.7 \pm 11.7$ & $52.9 \pm 11.2$ & $52.9 \pm 11$ & 0.001 \\
\hline Hospital stay (day)* & $6.5 \pm 14.6$ & $6.6 \pm 14.6$ & $6.5 \pm 14.6$ & $6.3 \pm 14.1$ & $7.04 \pm 15.6$ & 0.437 \\
\hline \multicolumn{7}{|l|}{ Gender** } \\
\hline Men & $15033(72.4)$ & $5488(26.4)$ & 3906 (18.8) & $4426(21.3)$ & $1213(5.8)$ & 0.001 \\
\hline Women & 5717 (27.6) & $4123(19.8)$ & $1035(4.9)$ & $506(2.4)$ & $53(0.26)$ & \\
\hline Smoking** & $5443(26.2)$ & $2313(11.1)$ & $1408(6.7)$ & $1385(6.6)$ & $337(1.6)$ & 0.001 \\
\hline Hypertension ${ }^{* *}$ & 7376 (35.5) & 4066 (19.6) & $1584(7.6)$ & $1372(6.6)$ & $354(1.7)$ & 0.001 \\
\hline Diabetes mellitus** & $4612(22.2)$ & $2243(10.8)$ & $1144(5.5)$ & $983(4.7)$ & $242(1.1)$ & 0.001 \\
\hline Hyperlipidaemia** & $3710(17.8)$ & $1726(8.3)$ & $854(4.1)$ & $910(4.4)$ & $220(1)$ & 0.467 \\
\hline
\end{tabular}

${ }^{*}$ Mean $\pm \mathrm{SD},{ }^{* *}$ Frequency and percentage. 
Table 2 Clinical characteristics in MI patients by educational levels in Iran, 2012-2013

\begin{tabular}{lllllll}
\hline Characteristic & Total & Illiterate & Primary & Secondary & University & P-Value \\
\hline VF & $511(2.5)^{*}$ & $232(1.1)$ & $116(0.56)$ & $132(0.64)$ & $31(0.15)$ & 0.728 \\
VT & $1198(5.8)$ & $508(2.4)$ & $275(1.3)$ & $328(1.5)$ & $87(0.42)$ & 0.002 \\
Lateral MI & $990(4.8)$ & $494(2.3)$ & $223(1.0)$ & $222(1.0)$ & $51(0.25)$ & 0.115 \\
Anterior MI & $4332(20.9)$ & $2013(9.7)$ & $1042(5.0)$ & $991(4.7)$ & $286(1.3)$ & 0.236 \\
Inferior MI & $7179(34.6)$ & $3094(14.9)$ & $1711(8.2)$ & $1882(9.0)$ & $492(2.4)$ & 0.001 \\
Posterior MI & $853(4.2)$ & $383(1.8)$ & $233(1.2)$ & $192(0.93)$ & $45(0.22)$ & 0.087 \\
STEMI & $15729(75.8)$ & $6988(44.4)$ & $3842(24.4)$ & $3882(24.6)$ & $1017(6.4)$ & 0.001 \\
Non-STEMI & $5021(24.2)$ & $2623(52.2)$ & $1099(21.8)$ & $1050(20.9)$ & $249(4.9)$ & 0.001 \\
PCl & $1431(6.9)$ & $343(1.6)$ & $372(1.7)$ & $549(2.6)$ & $167(0.80)$ & 0.001 \\
CABG & $539(2.6)$ & $244(1.1)$ & $122(0.59)$ & $127(0.61)$ & $46(0.22)$ & 0.12 \\
Lack of thrombolytic therapy & $9222(44.5)$ & $3903(18.8)$ & $2209(10.6)$ & $2481(11.9)$ & $629(3.0)$ & 0.001 \\
Chest pain & $2229(10.7)$ & $1000(4.8)$ & $633(3.0)$ & $446(2.1)$ & $150(0.72)$ & 0.001 \\
\hline
\end{tabular}

*Frequency and (\%).

VF- ventricular fibrillation; VT- ventricular tachycardia; MI-myocardial infarction; STEMI- ST-segment elevation myocardial infarction; NSTEMI- non ST-segment elevation myocardial infarction; PCI- Percutaneous Coronary Intervention; CABG- Coronary Artery Bypass Grafting.

Table 3 MI cases, CFR ${ }^{1}$ and IMR $^{2}$ for gender, age, and education in Iran, 2012-2013

\begin{tabular}{|c|c|c|c|c|}
\hline Gender & Age group & Education & Number (CFR \%) & IMR: $95 \% \mathrm{Cl}^{3}$ \\
\hline \multirow[t]{11}{*}{ Women } & $<65$ years $n=2690$ & Illiterate & 1533(56.9) & 7.09:6.13-8.19 \\
\hline & & Primary & $705(26.2)$ & $5.8: 4.57-7.36$ \\
\hline & & Secondary & 406(15.1) & $4.96: 3.53-6.79$ \\
\hline & & University & $46(1.7)$ & 15.37:7.69-30.7 \\
\hline & & Total women $<65$ & $2690(47)$ & $6.49: 5.7-7.2$ \\
\hline & $\geq 65$ years $n=3027$ & Illiterate & $2590(85.5)$ & 10.66:9.78-11.62 \\
\hline & & Primary & $330(10.9)$ & $5.58: 4.02-7.74$ \\
\hline & & Secondary & $100(3.3)$ & $3.49: 1.65-7.73$ \\
\hline & & University & $7(0.23)$ & $13.04: 1.83-19.6$ \\
\hline & & Total women $\geq 65$ & $3027(53)$ & 9.8:9-10.6 \\
\hline & Total women & & $5717(27.6)$ & $8.36: 7.8-8.9$ \\
\hline \multirow[t]{11}{*}{ Men } & $<65$ years $n=9814$ & Illiterate & 2197(22.3) & $5.68: 4.98-6.48$ \\
\hline & & Primary & $2767(28.2)$ & $5.74: 5.1-6.45$ \\
\hline & & Secondary & $3800(38.7)$ & $4.56: 4.06-5.11$ \\
\hline & & University & 1050(10.6) & $5.88: 4.89-7.06$ \\
\hline & & Total men $<65$ & $9814(65.3)$ & 5.3:4.9-5.6 \\
\hline & $\geq 65$ years $n=5219$ & Illiterate & $3291(63)$ & $8.07: 7.39-8.81$ \\
\hline & & Primary & $1139(21.8)$ & $7.24: 6.2-8.46$ \\
\hline & & Secondary & $626(12)$ & $6.57: 5.28-8.18$ \\
\hline & & University & 163(3.2) & $4.29: 2.73-6.72$ \\
\hline & & Total men $\geq 65$ & $5219(34.7)$ & $7.5: 7-8.1$ \\
\hline & & Total men & $15033(72.4)$ & $6.12: 5.8-6.43$ \\
\hline \multirow[t]{4}{*}{ Total } & & Illiterate & $9611(46.3)$ & $8.11: 7.7-8.5$ \\
\hline & & Primary & $4941(23.8)$ & $6.11: 5.6-6.6$ \\
\hline & & Secondary & 4932(23.8) & $4.85: 4.4-5.3$ \\
\hline & & University & $1266(6.1)$ & $5.81: 4.9-6.8$ \\
\hline
\end{tabular}

${ }^{1}$ Case fatality rate; ${ }^{2}$ In-hospital mortality rate (per 100 person-years); ${ }^{3}$ Confidence interval. 
Table 4 Modeling of HR (CI 95\%)* for MI mortality in educational levels in Iran, 2012-2013

\begin{tabular}{lllll}
\hline Models & & Illiterate & Primary level & Secondary \\
\hline 0 & Unadjusted HR & $1.4: 1.18-1.67 \mathrm{P}<0.001$ & $1.05: 0.87-1.27 \mathrm{P}=0.557$ & $0.81: 0.67-0.98 \mathrm{P}=0.037$ \\
1 & Adjusted for age and gender & $1.11: 0.93-1.34 \mathrm{P}=0.223$ & $0.96: 0.8-1.16 \mathrm{P}=0.716$ & $0.8: 0.66-0.97 \mathrm{P}=0.025$ \\
2 & Above + interaction of gender with EL & $1.7: 1.09-2.65 \mathrm{P}=0.019$ & $1.31: 0.82-2.07 \mathrm{P}=0.249$ & $1.19: 0.73-1.94 \mathrm{P}=0.47$ \\
3 & Above + past medical history & $1.69: 1.08-2.63 \mathrm{P}=0.021$ & $1.28: 0.81-2.04 \mathrm{P}=0.280$ & $1.18: 0.72-1.93 \mathrm{P}=0.49$ \\
4 & Above + treatment regime & $1.72: 1.1-2.7 \mathrm{P}=0.017$ & $1.32: 0.83-2.1 \mathrm{P}=0.237$ & $1.27: 0.78-2.08 \mathrm{P}=0.329$ \\
5 & Above + Ischemic Pattern Pain & $1.05: 0.87-1.26 \mathrm{P}=0.56$ & $0.86: 0.72-1.04 \mathrm{P}=0.143$ & $0.79: 0.66-0.96 \mathrm{P}=0.022$ \\
6 & Above + complication of Ml & $1.04: 0.87-1.25 \mathrm{P}=0.629$ & $0.85: 0.71-1.03 \mathrm{P}=0.114$ & $0.78: 0.64-0.95 \mathrm{P}=0.014$ \\
7 & Above + Ml Type & $1.05: 0.87-1.26 \mathrm{P}=0.575$ & $0.95: 0.75-1.05 \mathrm{P}=0.306$ & $0.78: 0.65-0.95 \mathrm{P}=0.015$ \\
\hline
\end{tabular}

*Hazard ratio (confidence interval 95\%).

Model2: age, gender and interaction of gender with EL. Model3: smoking + Type 2 Diabetes Mellitus + Hypertension + Hyperlipidaemia. Model4: PCI + CABG + Thrombolytic, model5: Chest Pain + pain left arm + dyspnea + sweating + vomiting + nausea + jaw pain. Model6: RBBB, LBBB, AF, VF, VT, Model7: STEMI + non-STEMI, MI Status.

$\mathrm{P}=0.039$ ), but in multivariate analysis, it was not significant (HR: 1.06, 95\% CI: $0.97-1.17, \mathrm{P}=0.172$ ).

\section{Discussion}

In this study, in-hospital mortality rate in women and men was respectively 8.36 and 6.12 in 100 person-years. This rate was 8.11 in the patients with no education and 5.81 in the patients with academic education. The mortality rate was higher in women than men and in the patients over 65 years than those under 65 years. The notable points in our study were avoidance of biases of selection and information and conduction of a hospitalbased, large study with the findings generalizable to the whole country. Cox analysis and modeling were other advantages of our work in comparison to the works conducted in similar countries where other analyses have been used due to the defined MI cohort.

In China, low education was associated with increased MI risk $(\mathrm{OR}=1.45)$ [6]. In our study, illiteracy was associated with increased death HR due to MI $(\mathrm{HR}=1.27)$ and the associated factors with death in illiterate patients were different from those in the patients with other

Table 5 The hazard ratio of factors associated with MI mortality in patients in Iran (2012-2013)

\begin{tabular}{|c|c|c|c|c|}
\hline \multirow[t]{2}{*}{ Factor } & \multicolumn{2}{|c|}{ Univariate analysis } & \multicolumn{2}{|c|}{ Multivariate cox model } \\
\hline & HR:Cl95\%* & P-Value & HR:Cl95\% & P-Value \\
\hline \multicolumn{5}{|l|}{ Gender } \\
\hline Men & Ref. & - & - & - \\
\hline women & $1.38: 1.27-1.5$ & 0.001 & $1.28: 1.17-1.40$ & 0.001 \\
\hline \multicolumn{5}{|l|}{ Education } \\
\hline Illiterate & $1.41: 1.18-1.67$ & 0.001 & $1.27: 1.06-1.52$ & 0.007 \\
\hline Primary & $1.05: 0.87-1.27$ & 0.557 & 0.93:0.77-1.13 & 0.503 \\
\hline Secondary & 0.78:0.62-0.99 & 0.041 & $0.72: 0.57-0.91$ & 0.006 \\
\hline High school & 0.83:0.67-1.02 & 0.083 & 0.82:0.66-1.01 & 0.06 \\
\hline University & Ref. & - & - & - \\
\hline Diabetes mellitus* & $1.1: 1-1.2$ & 0.039 & $1.06: 0.97-1.17$ & 0.172 \\
\hline Smoker* & $1.31: 1.2-1.42$ & 0.001 & $1.16: 1.06-1.27$ & 0.001 \\
\hline $\mathrm{VT}^{*}$ & $2.19: 1.93-2.49$ & 0.001 & $1.67: 1.46-1.90$ & 0.001 \\
\hline STEMI* & $3.27: 3.01-3.55$ & 0.001 & $1.32: 1.18-1.48$ & 0.001 \\
\hline RBBB* & $2.81: 2.23-3.55$ & 0.001 & 2.45:1.94-3.11 & 0.001 \\
\hline Chest pain* & 4.68:4.3-5.08 & 0.001 & $4.06: 3.73-4.43$ & 0.001 \\
\hline Lack of TT* & $1.91: 1.77-2.07$ & 0.001 & $1.57: 1.44-1.72$ & 0.001 \\
\hline $\mathrm{PCl}^{*}$ & $0.42: 0.34-0.53$ & 0.001 & $0.61: 0.49-0.77$ & 0.001 \\
\hline
\end{tabular}

"Hazard ratio (confidence interval 95\%).

VT- ventricular tachycardia; STEMI- ST-segment elevation myocardial infarction; RBBB- right bundle branch block; TT- thrombolytic therapy; PCI- percutaneous coronary intervention; *The variables were entered as dichotomous $(0 \& 1)$ and 0 was set as reference. 
educational levels. However, presence of main cardiovascular disease risk factors in the illiterate individuals indicates that disparity in post-MI mortality could be largely prevented through offering pre-hospital diagnostic and therapeutic services and hospital care to illiterate patients. Also, our findings are not consistent with a study in Iran, reporting that smoking, age, and gender were not determinants of in-hospital mortality due to MI [7]. Small sample could explain this inconsistency between the findings. The outcome of that study was 65 cases of in-hospital mortality and 500 cases of survival while our study investigated 2511 cases of mortality. One of strengths of our study was measurement of education by four levels, while in the study of Germany this variable was measured by two levels, low and high [17]. The rarity or lack of illiteracy in Germany and difficulty with fitting the German educational system into the International Standard Classification of Education could explain this classification. But, illiteracy is unfortunately high in Iran especially in women. In Germany, $19.1 \%$ of the patients with poor education died (long-term mortality) compared with $13.1 \%$ with higher education; the corresponding rates of in-hospital case fatality rate and in-hospital mortality rate in the present study were obtained respectively $46.2 \%$ and 11.3 per 100 person-years in patients with poor education, and $19.17 \%$ and 5.81 per 100 person-years in those with high education, higher compared to the longterm mortality in the study of Germany. In the study of Germany after confounding variables were controlled, the education had no effect on mortality in the total sample and the participants under 65 years. Also, low education was associated with increased death $(\mathrm{HR}=1.44)$ only in elderly patients. But, the education was an important variable and was associated with death $\mathrm{HR}$ in all ages in our study.

In Finland, the mortality rate was 5.21 in $35-$ to 64 year-old men and 11.31 in women [23]. Mortality rate in our study was higher than that obtained 30 days after MI in studies of Sweden and the UK with respectively 7.6 and 10.5 in 100 person-years. In Sweden and the UK, MI mortality was different for age, gender, blood pressure, diabetes, smoking, type of treatment, and type of MI, which is consistent with our study [24]. Although in our study, consistent with the study of Finland, death HR was higher in the patients with low SES and women, the mortality rate was higher in Iranian men compared to Finnish men and higher in Finnish women compared to Iranian women. Since the highest MI incidence worldwide has been reported in Finland, death HR seems to be higher in our study compared to the study of Finland. This requires further investigation. The inhospital case fatality rate in our study was similar to that in Puerto Ricans, in whom the mortality rate in men and women was reported respectively $8.6 \%$ and $6 \%$ [25].
The results of our study are in agreement with a study that examined the association of education with $\mathrm{MI}$ in the USA, reporting an association between low education and increased risk of fatal and non-fatal MI [26].

Being women, chest pain prior to arriving in hospital, lack of thrombolytic therapy, RBBB, smoking and STEMI were significantly associated with increased death HR. These findings are not consistent with the studies reporting a lower decrease in type 2 diabetes, hypertension, and smoking in the individuals with high education compared to those with low education [27-29]. This observation could be explained by higher physical activity among the illiterate individuals who possibly live in non urban regions. The difference in MI incidence and the associated mortality has been also reported by other studies among age groups and between genders, in agreement with our results. MI incidence is higher in men than women. In some studies, this incidence is higher in women than men and in some others it is relatively equal. The difference in mortality between men and women is dependent on age and type of MI (STEMI). Besides, biological factors could be the reason for this difference. In women, the type of MI is mainly non STEMI. Decreasing disparity between genders could contribute to the decrease in MI-associated mortalities [30,31]. Smoking caused an increase in postMI death HR in the patients while education was controlled [32,33]. Policy making and implementation of interventional programs in this group of patients could decrease the death risk. In view of the risk factors attributed to increased death risk in patients with different educational levels, the mortality due to MI (the most prevalent reason for death in Iran) could be decreased by implementing the programs adjusted to the mentioned risk factors at the community and case scale, such as offering special nursing services, and hence the concerns of health community professionals could be mitigated $[34,35]$.

\section{Limitations}

Failure to calculate mortality rate 28 days after MI incidence was a limitation of the present study. If this index is calculated, the possibility of comparing the findings with other studies' will increase. This index is recommended to be measured in future studies of Iran. Failure to measure income and occupation, and low number of cases with academic education in women were other limitations of the present study.

\section{Conclusions}

In this study, in-hospital mortality rate and case fatality rate due to MI were reported by age, gender, and education based on a hospital-based work in national scale in Iran. Also, in this study the factors relevant to the patients' mortality were modeled and determined in different educational levels. Being women, chest pain prior to 
arriving in hospital, lack of thrombolytic therapy, RBBB, VT, smoking, and STEMI were significantly associated with increased death risk. A disparity was noted in postMI mortality incidence in different educational levels in Iran. HR of death in illiterate patient was higher than in the patients with academic education. Identifying disparities per educational level could contribute to detecting the individuals at high risk, health promotion and care improvement by relevant planning and interventions in clinics and communities.

\section{Abbreviations}

Ml: Myocardial infarction; EL: Education level; SES: Socioeconomic status; IMIR: Iranian myocardial infarction registry; PCl: Percutaneous coronary intervention; CABG: Coronary artery bypass grafting; Cl: 95\% confidence intervals; NSTEMI: None ST-segment elevation myocardial infarction; STEMI: ST-segment elevation myocardial infarction; LBBB: Left bundle branch block; RBBB: Right bundle branch block; VF: Ventricular fibrillation; ECG: Electrocardiographic; VT: Ventricular tachycardia; AF: Atrial fibrillation.

\section{Competing interests}

The authors declare that they have no competing interests.

\section{Authors' contributions}

$A A, H S, A K$ and $H S$ designed the research protocol and supervised its implementation. AA designed Statistical analysis. AA, HS and AK drafted the article; HS, HS and AA conceptualized the article; HS defined the analytic approach. All of the authors reviewed drafts of the article and contributed to the conceptual framework. All authors read and approved the final manuscript.

\section{Authors' information}

${ }^{1}$ Member of Iranian Epidemiological Association. ${ }^{2}$ Social Health Determinants Research Center, Shahrekord University of Medical Sciences, Shahrekord, Iran. ${ }^{3}$ Social Determinants of Health Research Center, University of Social Welfare and Rehabilitation Sciences, Tehran, IR Iran. ${ }^{4}$ Safety Promotion and Injury Prevention Research Center, Shahid Beheshti University of Medical Sciences, Tehran, Iran

\section{Acknowledgments}

Data collection for this research was supported by the Cardiology Department, respectful personnel in treatment deputies of universities of medical sciences and the nurses in cardiology wards of hospitals across Iran, as well as cardiologists, officials, and advisors of Iran's Myocardial Infarction Registry Program. The funding sources played no role in the study design, data analysis, and manuscript writing, or in the decision to submit this manuscript for publication. This study was funded by Social Determinants of Health Research Center, University of Social Welfare and Rehabilitation Sciences (grant no.13609).

This work has been obtained from a PhD thesis of Epidemiology by the first author at Shahid Beheshti University of Medical Sciences. The study was approved by the Center for Non-Communicable Diseases Control and Department of Cardiovascular Diseases Prevention, Iran Ministry of Health and Medical Education (approval no. 305/837). Hereby, we gratefully thank them and Dr. Mehrabi, Dr. Etemad and all nurses and cardiologists across the country.

\section{Author details}

'Department of Epidemiology and Biostatistics, School of Public Health, Shahrekord University of Medical Sciences, Shahrekord, Iran. ${ }^{2}$ Cardiology Department, School of Medicine, Hajar Hospital, Shahrekord University of Medical Sciences, Shahrekord, Iran. ${ }^{3}$ Social Determinants of Health Research Center, University of Social Welfare and Rehabilitation Sciences, Tehran, IR, Iran. ${ }^{4}$ Safety Promotion and Injury Prevention Research center, Department of Epidemiology, School of Public Health, Shahid Beheshti University of Medical Sciences, 7th Floor, 2nd SBMU Headquarters Building, Parvaneh St. Velenjak Area, Chamran High Way, Tehran, Iran.
Received: 22 April 2014 Accepted: 12 November 2014

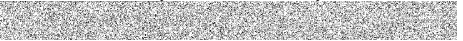

References

1. Hotchkiss JW, Davies CA, Dundas R, Hawkins N, Jhund PS, Scholes S, Bajekal M, O'Flaherty M, Critchley J, Leyland AH, Capewell S: Explaining trends in Scottish coronary heart disease mortality between 2000 and 2010 using IMPACTSEC model: retrospective analysis using routine data. BMJ 2014, 348:1088.

2. Ahmadi A, Soori H, Mehrabi Y, Etemad K, Samavat T, Khaledifar A: Incidence of acute myocardial infarction in Islamic Republic of Iran: a study using national registry data in 2012. East Mediterr Health J. in press.

3. Talaei M, Sarrafzadegan N, Sadeghi M, Oveisgharan S, Marshall T, Thomas GN, Iranipour R: Incidence of cardiovascular diseases in an Iranian population: The Isfahan cohort study. Arch Iran Med 2013, 16:138-144.

4. Jeemon P, Reddy KS: Social determinants of cardiovascular disease outcomes in Indians. Indian J Med Res 2010, 132:617-622.

5. Talbott EO, Rager JR, Brink LL, Benson SM, Bilonick RA, Wu WC, Han YY: Trends in acute myocardial infarction hospitalization rates for US States in the CDC tracking network. PLOS One 2013, 8:e64457.

6. Hu B, Li W, Wang X, Liu L, Teo K, Yusuf S: Marital status, education, and risk of acute myocardial infarction in Mainland China: the INTER-HEART study. J Epidemiol 2012, 22:123-129.

7. Donyavi T, Naeini KH, Nedjat S, Vahdaninia M, Najafi M, Montazeri A: Socioeconomic status and mortality after acute myocardial infarction: a study from Iran. Int J Equity Health 2011, 10:9.

8. Lopez R: Income inequality and self-rated health in US metropolitan areas: a multi-level analysis. Soc Sci Med 2004, 59:2409-2419.

9. Cavelaars AE, Kunst AE, Geurts JJ, Crialesi R, Grotvedt L, Helmert U, Lahelma E, Lundberg O, Matheson J, Mielck A, Mizrahi A, Mizrahi A, Rasmussen NK, Regidor E, Spuhler T, Mackenbach JP: Differences in self reported morbidity by educational level: a comparison of 11 western European countries. J Epidemiol Community Health 1998, 52:219-227.

10. Huisman M, Read S, Towriss CA, Deeg DJ, Grundy E: Socioeconomic inequalities in mortality rates in old age in the world health organization Europe Region. Epidemiol Rev 2013, 35:84-97.

11. Lammintausta A, Immonen-Raiha P, Airaksinen JK, Torppa J, Harald K, Ketonen M, Lehto S, Koukkunen H, Kesäniemi AY, Käriä-Koskenkari P, Salomaa V: Socioeconomic inequalities in the morbidity and mortality of acute coronary events in Finland: 1988 to 2002. Ann Epidemiol 2012, 22:87-93.

12. Machon M, Aldasoro E, Martinez-Camblor P, Calvo M, Basterretxea M, Audicana C, Alonso $E$, Tobalina MA, Larrañaga N: Socioeconomic differences in incidence and relative survival after a first acute myocardial infarction in the Basque Country, Spain. Gac Sanit 2012, 26:16-23.

13. Manrique-Garcia E, Sidorchuk A, Hallqvist J, Moradi T: Socioeconomic position and incidence of acute myocardial infarction: a meta-analysis. J Epidemiol Community Health 2011, 65:301-309.

14. Mobasheri M, Ahmadi A, Khaledifar B: Comparison of the papers published in journal of Shahrekord University of medical sciences with those published in other medical journals of Iran in view of methodology. Life Science Journal 2013, 10:3640-3645.

15. Hernan MA, Hernandez-Diaz S, Robins JM: A structural approach to selection bias. Epidemiology 2004, 15:615-625.

16. Yarnell J, Yu S, McCrum E, Arveiler D, Hass B, Dallongeville J, Montaye M, Amouyel $P$, Ferrières J, Ruidavets $J B$, Evans $A$, Bingham $A$, Ducimetière $P$ : Education, socioeconomic and lifestyle factors, and risk of coronary heart disease: the PRIME Study. Int J Epidemio/ 2005, 34:268-275.

17. Kirchberger I, Meisinger $C$, Goluke $H$, Heier M, Kuch B, Peters A, Quinones $P A$, von Scheidt W, Mielck A: Long-term survival among older patients with myocardial infarction differs by educational level: results from the MONICA/KORA myocardial infarction registry. Int J Equity Health 2014, 13:19

18. Krieger N, Williams DR, Moss NE: Measuring social class in US public health research: concepts, methodologies, and guidelines. Annu Rev Public Health 1997, 18:341-378.

19. Silventoinen $\mathrm{K}$, Lahelma $\mathrm{E}$ : Health inequalities by education and age in four Nordic countries, 1986 and 1994. J Epidemiol Community Health 2002, 56:253-258

20. Montazeri A, Goshtasebi A, Vahdaninia M: Educational inequalities in selfreported health in a general Iranian population. BMC Res Notes 2008, 1:50. 
21. Ahmadi A, Soori H, Mehrabi Y, Etemad K, Khaledifar A: Epidemiologic pattern of myocardial infarction and modeling risk factors relevant to in-hospital mortality: the first results from Iranian Myocardial Infarction Registry. Kardiol Pol. in press.

22. Mendis S, Thygesen K, Kuulasmaa K, Giampaoli S, Mähönen M, Lisheng L: World Health Organization definition of myocardial infarction: 2008-09 revision. Int J Epidemiol 2011, 40:139-146.

23. Havulinna AS, Paakkonen R, Karvonen M, Salomaa V: Geographic patterns of incidence of ischemic stroke and acute myocardial infarction in Finland during 1991-2003. Ann Epidemiol 2008, 18:206-213.

24. Chung SC, Gedeborg R, Nicholas O, James S, Jeppsson A, Wolfe C, Heuschmann P, Wallentin L, Deanfield J, Timmis A, Jernberg T, Hemingway H: Acute myocardial infarction: a comparison of short-term survival in national outcome registries in Sweden and the UK. Lancet 2014, 383:1305-1312.

25. Zevallos JC, Yarzebski J, Gonzalez JA, Banchs HL, Garcia-Palmieri M, Mattei $H_{\text {, }}$ Ayala J, González M, Torres V, Ramos IN, Pericchi LR, Torres DA, González MC, Goldberg RJ: Incidence, in-hospital case-fatality rates, and management practices in Puerto Ricans hospitalized with acute myocardial infarction. PR Health Sci I 2013, 32:138-145.

26. Kucharska-Newton AM, Harald K, Rosamond WD, Rose KM, Rea TD, Salomaa $\mathrm{V}$ : Socioeconomic indicators and the risk of acute coronary heart disease events: comparison of population-based data from the United States and Finland. Ann Epidemiol 2011, 21:572-579.

27. Korhonen J, Koskinen P: Acute myocardial infarction. A study of the sex distribution, immediate mortality, age distribution, incidence of hypertension and diabetes, and the effect of the seasons in a series of 376 cases. Ann Med Intern Fenn 1960, 49:247-254.

28. Ahmadi A, Hasanzadeh J, Rajaeifard A: Metabolic Control And Care Assessment in Patients with Type2Diabetes In Chaharmahal \& Bakhtiyari Province 2008. Iranian J Endocrinol Metab 2009, 11:33-39.

29. Kautzky-Willer A, Dorner T, Jensby A, Rieder A: Women show a closer association between educational level and hypertension or diabetes mellitus than males: a secondary analysis from the Austrian HIS. BMC Public Health 2012, 12:392.

30. Ahmadi A, Soori H, Sajjadi H, Nasri H: Current status of the clinical epidemiology of myocardial infarction in men and women: the data of 20750 Ml patients in Iran. Int I Prev Med. in press.

31. Garcia-Garcia C, Molina L, Subirana I, Sala J, Bruguera J, Aros F, Fiol M, Serra J, Marrugat J, Elosua R: Sex-based Differences in Clinical Features, Management, and 28-day and 7-year Prognosis of First Acute Myocardial Infarction. RESCATE II Study. Rev Esp Cardiol 2014, 67:28-35.

32. Radomska E, Sadowski M, Kurzawski J, Gierlotka M, Polonski L: ST-segment elevation myocardial infarction in women with type 2 diabetes. Diabetes Care 2013, 36:3469-3475.

33. Gnavi R, Canova C, Picariello R, Tessari R, Giorda C, Simonato L, Costa G: Mortality, incidence of cardiovascular diseases, and educational level among the diabetic and non-diabetic populations in two large Italian cities. Diabetes Res Clin Pract 2011, 92:205-212.

34. Oliver MF, Opie LH: Management of acute myocardial infarction. Lancet 2014, 383(9915):409-410

35. Nasri H, Behradmanesh S, Ahmadi A, Baradaran A, Nasri P, Rafieian-Kopaei M: Association of serum lipids with level of blood pressure in type 2 diabetic patients. J Renal Inj Prev 2014, 3:43-46.

\section{doi:10.1186/s12939-014-0116-0}

Cite this article as: Ahmadi et al:: Relationship between risk factors and in-hospital mortality due to myocardial infarction by educational level: a national prospective study in Iran. International Journal for Equity in Health 2014 13:116.

\section{Submit your next manuscript to BioMed Central and take full advantage of:}

- Convenient online submission

- Thorough peer review

- No space constraints or color figure charges

- Immediate publication on acceptance

- Inclusion in PubMed, CAS, Scopus and Google Scholar

- Research which is freely available for redistribution

Submit your manuscript at www.biomedcentral.com/submit
Ciomed Central 